\title{
Modeling the Term Structure of Exchange Rate Expectations*
}

\author{
Christian Bauer ${ }^{\dagger}$ \\ University of Trier, Germany \\ E-mail: bauer@uni-trier.de \\ and \\ Sebastian Horlemann \\ UniCredit Group/HVB, Munich
}

\begin{abstract}
We develop a model of the term structure of exchange rate expectations by integrating interest parity into a microstructure model of foreign exchange and national bond markets. The spot rate's reaction to typical shocks is able to reproduce standard results (e.g. overshooting) without reference to other frictions like rigid prices.

Both countries' yield curves influence the semi-elasticity of the spot exchange rate. Opposing exchange rate expectations for short and for long horizons reduce interest rate effects.

Finally, we show that not all rational methods of expectation formation are mutually consistent and induce model ambiguity as a genuine source of the UIP puzzle.
\end{abstract}

Key Words: Exchange rates; Expectation; Term structure; Interest parity. JEL Classification Numbers: F31, D84, E43.

\section{INTRODUCTION}

In the globalized economy, exchange rates are the most important class of prices. Beside the spot exchange rate, expectations of its future value drive economic decisions. The implications of changes in spot and expected exchange rates are both reason and fundament of the analyses of exchange rate behavior. The pressure of an appreciation and depreciation,

* The first author gratefully acknowledges financial support by the Deutsche Forschungsgesellschaft (German Science Foundation)

$\dagger$ University of Trier, FB IV - Economics, D-54286 Trier, Germany.

303 
respectively, on the exchange rate influences the movement of capital and investment. Investments and their yields in the home or foreign country depend critically on the expected exchange rate in the future. The exchange rate risk determines the risk premium for investments in a foreign country and has led to many financial instruments used to hedge against this risk. Furthermore, the competitiveness of exported and imported goods fundamentally depend on the exchange rate. Also, the exchange rate policy of a central bank is influenced by the expectations of the future values of the exchange rate and vice versa.

The economic literature on exchange rates can be roughly separated into crises and non crises papers. This paper contributes the second strand of the literature which describes the influence of exchange rates on the economy and on economic decisions in general without distinct reference to crisis situations. In particular, our term structure model of exchange rate expectations yields a potential explanation for two puzzling empirical characteristics: the uncovered interest parity (UIP) puzzle and the inconsistency of the reaction function of the spot exchange rate on changes of the spot interest rate.

We integrate the interest parity idea into a modern microstructure model of foreign exchange and national bond markets and develop a model of the term structure of exchange rate expectations. Our results extend the existing literature on UIP in two ways. Firstly, we show that the semielasticity of the spot exchange rate on interest rate changes depends not only on determinants of the financial markets and fundamentals, but also on the term structure of interest rates in both countries. Secondly, we show that combining UIP with interest rate term structures comes along with a variety of rational expectations on the future path of the exchange rate.

UIP depends on the simple idea of arbitrage limiting the deviation of returns in different countries, i.e. expected exchange rate changes equal the respective interest rate differentials. The term structure of interest rates of two countries thus implies a term structure of exchange rate expectations. However, various costs, e.g. of information gathering and processing or risk premia, induce a certain stickiness which limits the arbitrage process.

Albeit the idea is intriguing, the majority of empirical studies (see e.g. Frankel and Froot (1987, 1989), Grilli and Roubini (1995, 1996), and Mark and $\mathrm{Wu}(1998)$ ) reject this simple relationship. In fact, the random walk is typically seen as a hard to beat benchmark in predicting exchange rates. A number of recent studies, however, (see e.g. Chinn and Meredith (2004, 2005), and Chaboud and Wright (2005)) find empirical evidence supporting UIP for different maturities. Incia and Lub (2007) validate the UIP for short maturities. In their sample, UIP fails on the basis of long-maturity contracts, but currency futures returns are predicted correctly. 
This empirical evidence is not robust to changes in the used sample (country pairs, period, and maturities) and the assumed theoretical model. Explanations for the empirical failure of UIP like peso problems, learning effects, rational bubbles, and variable risk-premia are discussed in a number of surveys (e.g. Froot and Thaler (1990), Lewis (1995), and Deutsche Bundesbank (2005)). While conventional approaches are troubled by significant deficiencies, Deutsche Bundesbank (2005) reviews models based on heterogeneous traders as promising and challenging new ways to analyze UIP.

As we will elaborate in the following sections, our model indicates two main sources for the diversity of the empirical results. Firstly, most empirical models work with a fixed maturity. This may lead to biased results. If the expectation of the exchange rate change is proxied by its realization, different maturities imply the influence of different shocks. The evolution of the spot rate is the result of heterogeneous agents rearranging their portfolios of national and international bonds with varying maturities. Changes of the term structure and the exchange rate expectations influence the current net demand for the currencies. Thus the evolution path of the exchange rate depends on the entire term structure. Secondly, expectation building is inevitably ambiguous if UIP is extended to the term structure. As we show below, even the very simple model presented here, leaves room for at least two types of rational expectations which are not mutually consistent. This ambiguity might also contribute to the controversial empirical results. The results of studies which use revolving short term investments as an approximation for long term bonds to circumvent the overlapping data problem as well as studies which concentrate on a single maturity, therefor have to be interpreted with care.

The model of Cox et al. (1985b) serves as a cornerstone for modeling the term structure of interest rates and its implications. As interest rates interact with exchange rates and vice versa, an approach of investigating the expectations needs to take the term structure into consideration. Similar to the term structure, there exist investors with different preferences regarding the length and other characteristics of investment opportunities. Consequently, various expectations at different future times are formed.

The remainder of the paper is organized as follows. First, the underlying model and the main results of the papers of Cox et al. (1985a,b) are introduced in section 2. In section 3, expectations of future values of the exchanges rates are evaluated. There are several rational, but mutually inconsistent, methods of building expectations. In subsections 3.1 and 3.2, two different approaches of calculating the expected exchange rates and their depreciation rates are presented. The results are compared in section 3.3 and visualized in section 3.4. In section 4, we generalize the reaction function of the spot exchange rate on changes of the basic economic 
variables like the spot interest rate. The semi-elasticity of the spot exchange rate on interest rate changes depends on both the term structure of interest rates in both countries and determinants of the financial markets. The summary concludes. ${ }^{1}$

\section{THE COX, INGERSOLL, AND ROSS (1985B) FRAMEWORK}

Cox et al. (1985a) develop a general equilibrium asset pricing model based on a partial differential equation. The main result is the endogenously determined price of any asset in terms of the underlying variables in the economy. In Cox et al. (1985b), the term structure of interest rates, which describes the relationship among the yields on default-free securities that differ only in their term to maturity, is deduced from the general model. On the one hand, this model analyzes the determinants and reaction functions of the term premiums. On the other hand, it also reflects several well known approaches of the term structure, like the expectations hypothesis, the liquidity hypothesis, and the market segmentation hypothesis.

We will focus on the spot interest rate dynamics, which are modeled by a continuous mean reverting time first-order autoregressive process with variance of the innovations $\sigma^{2}$. The variable $\theta$ is the long-term value of the spot interest rate $r$ and $\kappa$ is the speed of adjustment. We adopt the parameter restrictions given in Cox et al. (1985b).

$$
\sigma^{2}>0, \lambda<0, \kappa>0, \theta>0, \text { and } \kappa>|\lambda|
$$

This structure leads to an interest rate behavior, which is consistent with many stylized facts. Negative spot rates are precluded and if the spot rate reaches zero, it will subsequently become positive with probability 1 . The absolute variance increases with an increase in $r$. The condition on $\lambda$ ensures positive premiums. $\kappa>0$ and $\theta>0$ ensure the mean reversion property of the spot interest rate, i.e. $r$ is elastically pulled toward $\theta$.

The bond prices are calculated as follows:

$$
P(r, t, T)=A(t, T) e^{-B(t, T) r} .
$$

\footnotetext{
${ }^{1}$ The appendix is available form the authors upon request. It contains a list of the used notation, some calculations on the formal representation of a weak form of the liquidity preference hypothesis used to limit the variations of the parameters in the sensitivity analysis, and a sensitivity analysis of the expected total one period return of a bond within the Cox et al. (1985b) framework.
} 
Using the notation of Brown and Dybwig (1986), i.e. $\phi_{1}=\left[(\kappa+\lambda)^{2}+2 \sigma^{2}\right]^{\frac{1}{2}}$, $\phi_{2}=\frac{\kappa+\lambda+\phi_{1}}{2}$, and $\phi_{3}=\frac{2 \kappa \theta}{\sigma^{2}}, A(t, T)$ and $B(t, T)$ can be written as:

$$
\begin{aligned}
& A(t, T) \equiv\left(\frac{\phi_{1} e^{\phi_{2}(T-t)}}{\phi_{2}\left(e^{\phi_{1}(T-t)}-1\right)+\phi_{1}}\right)^{\phi_{3}} \\
& B(t, T) \equiv \frac{e^{\phi_{1}(T-t)}-1}{\phi_{2}\left(e^{\phi_{1}(T-t)}-1\right)+\phi_{1}} .
\end{aligned}
$$

Bonds are commonly quoted in terms of yields rather than prices. For the discount bonds we thus use the yield-to-maturity $R(r, t, T)$ defined by:

$$
\begin{aligned}
P(r, t, T) & =e^{-(T-t) R(r, t, T)} \\
R(r, t, T) & =\frac{r B(t, T)-\ln (A(t, T))}{(T-t)} .
\end{aligned}
$$

As maturity nears, the yield-to-maturity approaches the current spot interest rate independently of any of the parameters: $\lim _{T \rightarrow t} R(r, t, T)=r$. For longer and longer maturities, the yield approaches a limit which is independent of the spot interest rate:

$$
R l=R(r, t, \infty)=\frac{2 \kappa \theta}{\gamma+\kappa+\lambda} .
$$

The long-term yield (6) and the expression

$$
R g=\frac{\kappa \theta}{\kappa+\lambda}
$$

determine the appearance of the term structure.

Additionally, the condition $R(r, t, \infty)>\theta$ ensures a weak form of liquidity preference. The return of bonds with a long time-to-maturity is assumed to be higher than the return from repeatedly investing in bonds with shorter time-to-maturity if the maturity date is in the sufficiently distant future. ${ }^{2}$

\footnotetext{
${ }^{2}$ Using $\ln (1+x) \approx x$, this assumption can be rewritten as:

$$
e^{r(t) \Delta} e^{E(r(t+\Delta) \mid r(t)) \Delta} \cdots e^{E(r(T) \mid r(t)) \Delta}<e^{R(r, t, T)(T-t)} .
$$
}

Analogously, $R^{*}\left(r^{*}, t, \infty\right)>\theta^{*}$ is assumed. 


\section{THE EXPECTED EXCHANGE AND DEPRECIATION RATES}

In this section, the term structure of exchange rate expectations and expectations of the future depreciation rates are formed. We analyze the structure exchange rate expectations in a two country $(X$ and $Y$ ) model without capital controls. All variables used to describe the economy of country $Y$ are indicated by ${ }^{*}$. We use the price quotation from country $X$ 's point of view to describe the exchange rate or the expectation of the future exchange rate. We apply Cox et al. (1985b) for modeling the term structure of each of the two countries. There is no trading of goods between the countries. The only way the expectations of the future exchange rate appreciation and depreciation, respectively, are evolved is that of different investment opportunities in bonds. That is, the investors observe the term structure of their own country and that of the foreign country. Differences in yields-to-maturity are seen as the reason for changes in the exchange rate in the future. ${ }^{3}$

There are several possibilities of calculating an expectation of the exchange rate at a future point of time as well as there exist various ways of evolving the particular expected depreciation rates. We present two approaches explained in detail in the following sections.

FIG. 1. Schematic description of two approaches to form rational expectations on the term structure of exchange rate expectations

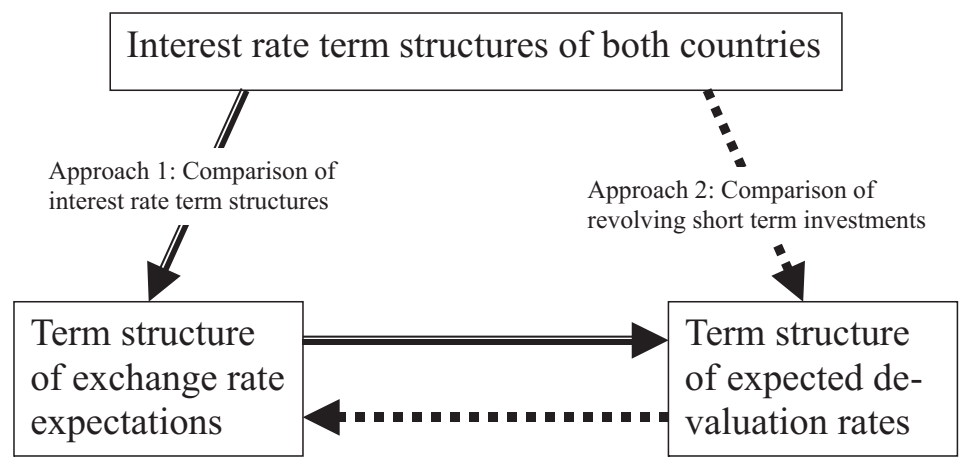

The first approach nests the idea of UIP with the interest rate term structures. The second approach, calculates the term structure of expected

\footnotetext{
${ }^{3}$ Alternatively, the model of Cox et al. (1985b) could be generalized to an open economy model, e.g. by introducing state variables describing the foreign country, e.g. Pavlova and Rigobon (2007).
} 
devaluation rates from the expectation of the short term interest rate differential derived from the interest rate term structure. The term structure of expected devaluation rates and the term structure of exchange rate expectations are two sides of the same medal and can be converted into each other.

\subsection{Approach Number One}

The first way to form an expectation on the term structure of exchange rate expectations simply nests the idea of UIP with the interest rate term structures of Cox et al. (1985b). The expectation of the future spot exchange rate at any future time $s$ is calculated from the respective interest differential using the no arbitrage condition. As the model assumes continuous payments of interest, we must distinguish between the yield-tomaturity $R(r, t, T)$ and the total return $R(r, t, T)^{T R}$, which can be written as:

$$
R(r, t, T)^{T R}=e^{R(r, t, T) \cdot(T-t)}-1,
$$

where $T-t$ stands for the time-to-maturity. The no arbitrage condition is

$$
\underbrace{\frac{\mathcal{E}_{T}^{e}}{\mathcal{E}_{t}}\left(1+R^{*}\left(r^{*}, t, T\right)^{T R}\right)}_{\text {expected final amount foreign investment }}=\underbrace{1+R(r, t, T)^{T R}}_{\text {final amount home investment }}
$$

Equation (9) is equivalent to

$$
R(r, t, T)^{T R}=\frac{1}{P(r, t, T)}-1
$$

and thus the solution to (10) is

$$
\begin{aligned}
\mathcal{E}_{T}^{e} & =\frac{1+R(r, t, T)^{T R}}{1+R^{*}\left(r^{*}, t, T\right)^{T R}} \mathcal{E}_{t} \\
& =\frac{P^{*}\left(r^{*}, t, T\right)}{P(r, t, T)} \mathcal{E}_{t} .
\end{aligned}
$$

Thus, the interest rate term structure defines the term structure of exchange rates. ${ }^{4}$

We use the term structure of exchange rate expectations to calculate the expected depreciation rate. Taking the values of the expected exchange

\footnotetext{
${ }^{4}$ The logarithm of (12) yields the well known equivalence of expected exchange rate change and interest rate differential, if the approximation $\ln (1+x)=x$ is applied. However, for longer maturities the total return is large and thus the use of this approximation appears not justified.
} 
rates at time $s$ and $s+\Delta$ the expected depreciation rate can be written as follows:

$$
\mathbb{E}^{1}\left(d_{s}\right)=\left(\frac{\mathcal{E}_{s+\Delta}^{e}-\mathcal{E}_{s}^{e}}{\mathcal{E}_{s}^{e}}\right)_{1} .
$$

The index $(\cdot)_{1}$ is introduced to differentiate between the first and the second approach. Positive values of (14) represent an expected depreciation of the exchange rate. Negative values indicate an appreciation.

\subsection{Approach Number Two}

Analogously to equation (14), the expected total one period returns ETR $(\Delta)$ and the ETR $(\Delta)^{*}$ can be used to calculate a second expectation of the one period depreciation rate.

The idea of UIP implies that the expected rate of exchange rate depreciation equals the respective expected interest rate differential. In contrast to the traditional version of UIP, both investments bear uncertainty, as both future spot interest rates and the future exchange rates are unknown. The no arbitrage condition conditional at the information at time $t$ for investing one unit of currency of country $X$ at the future time $s$ in either country $X$ or in country $Y$ is given by:

$$
\underbrace{\left(1+\mathbb{E}_{t}\left(R^{*}\left(r^{*}(s), s, s+\Delta\right)^{T R}\right)\right) \frac{\mathcal{E}_{s+\Delta}^{e}}{\mathcal{E}_{s}^{e}}}_{\text {expected final amount foreign investment }}=\underbrace{1+\mathbb{E}_{t}\left(R(r(s), s, s+\Delta)^{T R}\right)}_{\text {expected final amount home investment }} .
$$

This condition yields a second type of expectation for the term structure of devaluation rates, denoted with the index $(\cdot)_{2}$ :

$$
\begin{aligned}
\mathbb{E}^{2}\left(d_{s}\right) & =\left(\frac{\mathcal{E}_{s+\Delta}^{e}-\mathcal{E}_{s}^{e}}{\mathcal{E}_{s}^{e}}\right)_{2} \\
& =\frac{\frac{1+\mathbb{E}_{t}\left(R(r(s), s, s+\Delta)^{T R}\right)}{1+\mathbb{E}_{t}\left(R^{*}\left(r^{*}(s), s, s+\Delta\right)^{T R}\right)} \mathcal{E}_{s}^{e}-\mathcal{E}_{s}^{e}}{\mathcal{E}_{s}^{e}} \\
& =\frac{\mathbb{E}_{t}\left(R(r(s), s, s+\Delta)^{T R}\right)-\mathbb{E}_{t}\left(R^{*}\left(r^{*}(s), s, s+\Delta\right)^{T R}\right)}{1+\mathbb{E}_{t}\left(R^{*}\left(r^{*}(s), s, s+\Delta\right)^{T R}\right)},
\end{aligned}
$$

Obviously, the difference of the expected total one period returns determines the expected depreciation rate for any time $s$. According to the simple, risk-neutral efficient markets hypothesis the relevant interest rate differential is the optimum predictor of the future exchange rate depreciation.

Moreover, this term structure of depreciation rates can be transformed into a term structure of exchange rate expectations. Starting from the 
current spot exchange rate at time $t$, the exchange rate expectations can be iteratively calculated as follows:

$$
\mathcal{E}_{s+\Delta}^{e}=\frac{\mathbb{E}_{t}\left(R(r(s), s, s+\Delta)^{T R}\right)-\mathbb{E}_{t}\left(R^{*}\left(r^{*}(s), s, s+\Delta\right)^{T R}\right)}{1+\mathbb{E}_{t}\left(R^{*}\left(r^{*}(s), s, s+\Delta\right)^{T R}\right)} \mathcal{E}_{s}^{e}+\mathcal{E}_{s}^{e}
$$

\subsection{Comparison of the two approaches}

In the previous subsections, two different approaches to form rational expectations on the term structure of exchange rates and depreciation rates have been presented. This poses the question whether these two expectations are different, show similar structures or are even the same. While we use UIP directly in the first approach, in the second approach UIP in expectation is applied to short term investments in the future, which are stringed together to form the entire expected exchange rate term structure.

The expectations hypothesis leads to the conclusion that both expected depreciation rates (and consequently also the expected exchange rates) need to be the same. If one considers the opportunity of investing in either bonds in country $X$ or in bonds in country $Y$, the expectations hypothesis states that the return from holding a long-term bond, e.g. with time-to-maturity $s+\Delta-t$, is the same as rolling over a sequence of short-term bonds (here short-term is equivalent to one period). Consequently, the expected exchange rate at time $s+\Delta-t$ is the same for holding a long-term bond with time-to-maturity $s+\Delta-t$ or for reinvesting in short-term bonds repeatedly. The same argument is assumed to be valid for a long-term bond with time-to-maturity $s-t$. Hence, the calculated depreciation rates using the term structure of exchange rate expectations stemming from the first approach must equal the depreciation rate resulting from the difference of the expected short term returns at time $s$, such that:

$$
\left(\frac{\mathcal{E}_{s+\Delta}^{e}-\mathcal{E}_{s}^{e}}{\mathcal{E}_{s}^{e}}\right)_{1}=\left(\frac{\mathcal{E}_{s+\Delta}^{e}-\mathcal{E}_{s}^{e}}{\mathcal{E}_{s}^{e}}\right)_{2} .
$$

Under the assumption of liquidity preference, however, this argumentation fails. The equality of yields from roll-over short term investments and long term investment assumed by the expectations hypothesis is not valid if a liquidity preference exists. Thus both approaches for the term structure of exchange rate expectations and depreciation rate expectations differ.

Given complete markets for not only the spot exchange rate and bonds but also for the respective futures, swaps and other derivatives, both expectations could be realized in these markets. Thus arbitrage trading would force an equalizing of the derivatives' prices except for transaction costs and premia for the issuer risk. The next step in our research is to empirically test the relevance and compare these approaches on market data. 
In section 3.4, we investigate various examples of the term structure of both expected depreciation rates and both expected exchange rates. In some examples a similar development can be observed, whereas in other examples the paths differ from each other significantly.

\subsection{Examples: Analysis and Visualization}

In this section, the results acquired in section 3.1 and section 3.2 are used to interpret the term structure of interest rates, exchange rate expectations, and depreciation rate expectations of various examples of two economies. We visualize and interpret the results of both approaches for the calculation of the expectations. The examples are chosen such that the long-term yields are mostly the same to simplify the sensitivity analysis. ${ }^{5}$ In the following, the current time $t$ is standardized to zero and the current exchange rate $\mathcal{E}_{0}$ equals one. For numerical reasons, we choose the length of a period to be 0.01 . This choice is arbitrary and doesn't affect the results.

\section{Example 1:}

TABLE 1.

Parameter values used in example 1: spot interest rate $r$ and parameters of the spot interest rate process: mean reversion $\kappa$, long term value $\theta$, variance $\sigma$; market risk parameter $\lambda$; long term yield $\frac{2 \kappa \theta}{\gamma+\kappa+\lambda}$, and shape parameter $\frac{\kappa \theta}{\kappa+\lambda}$;

\begin{tabular}{|c|c|c|}
\hline Variable & Country $X$ & Country $Y$ \\
\hline$r:$ & $0.055(5.5 \%)$ & $0.055(5.5 \%)$ \\
$\kappa:$ & 0.8 & 0.5 \\
$\theta:$ & $0.03(3 \%)$ & $0.03(3 \%)$ \\
$\sigma:$ & 0.5 & 0.5 \\
$\lambda:$ & -0.4 & -0.4 \\
$\frac{2 \kappa \theta}{\gamma+\kappa+\lambda}:$ & $0.0396(3.96 \%)$ & $0.0368(3.68 \%)$ \\
$\frac{\kappa \theta}{\kappa+\lambda}:$ & $0.06(6 \%)$ & $0.15(15 \%)$ \\
\hline
\end{tabular}

The economies of both countries are very similar. They only differ from each other in the difference of the parameters describing the respective speed of adjustment of the spot rate. Figure 2(a) shows the term structure in both countries.

Approach 1: (Based on term structure) As one can see, although the spot rates are the same, the difference in $\kappa$ leads to different term structures and different values of the long-term yields (6). Apparently, the spot rate of country $X$ is humped and in excess of the long-term yield. The term structure of country $Y$ is also humped, however, the maximum is higher than the maximum of country $X$ 's term structure. This difference accounts

\footnotetext{
${ }^{5}$ For deeper understanding of the structure of the expected future one period total returns refer to section A.3 in the appendix.
} 
FIG. 2. Example 1: Term structures of interest rates, expected exchange rates, expected depreciation rates;

(a) Term Structures: country $X$ solid, country $Y$ dashed

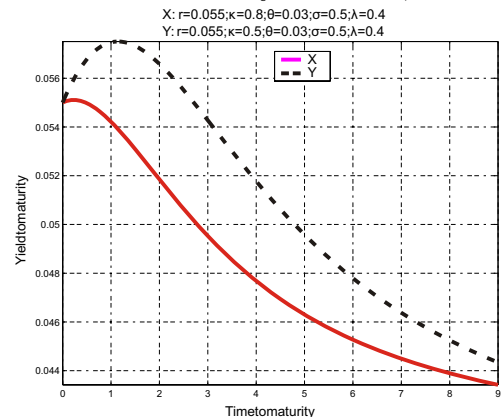

(b) Expected Exchange Rates: approach 1 based on term structures solid, approach 2 based on expected spot rates dashed

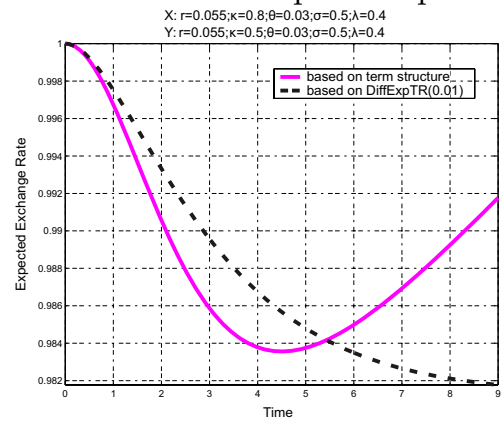

(c) Expected Depreciation Rates: approach 1 based on term structures solid, approach 2 based on expected spot rates dashed

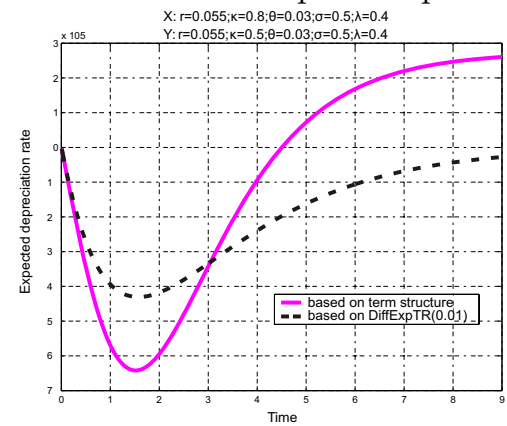

for the appreciation of the expected exchange rate (solid line) as shown in figure 2(b). The appreciation reaches its maximum approximately at time 4.5 , depending on the difference of the interest rates and the time to matu- 
rity. Consequently, the expected rate of depreciation becomes positive at this point of time (see figure 2(c)). In the long run, the expected exchange rate will return to unity due to the small difference in the long term yields.

Approach 2: (Based on expected spot rates) The dashed line describes the development of the expected rate of depreciation based on the difference of the expected spot rates. The spot rate of country $X$ is expected to return faster to its long term value $\theta$ and is thus expected to remain lower than country $Y$ 's spot rate. Consequently, the dashed line in figure 2(b) shows a constant appreciation. It is not surprising that the rate seems to become zero in the long-run as the expectation in the long-run can be approximated by $e^{\theta \cdot 0.01}-1$ in both countries. Over all the expected depreciation rate based on the term structure seems to be more volatile.

The phenomenon of an appreciation in the beginning, followed by a depreciation is not unknown at all. Overshooting and undershooting of the exchange rate is observed on foreign exchange markets as well as it is common to standard economic models. One explanation is that the equilibrium on the foreign exchange rate market is reached faster than one on the market for goods (see e.g. Krugman and Obstfeld (2003)).

\section{Example 2:}

TABLE 2.

Parameter values used in example 2: spot interest rate $r$ and parameters of the spot interest rate process: mean reversion $\kappa$, long term value $\theta$, variance $\sigma$; market risk parameter $\lambda$; long term yield $\frac{2 \kappa \theta}{\gamma+\kappa+\lambda}$, and shape parameter $\frac{\kappa \theta}{\kappa+\lambda}$;

\begin{tabular}{|c|c|c|}
\hline Variable & Country X & Country Y \\
\hline$r:$ & $0.055(5.5 \%)$ & $0.06(6 \%)$ \\
$\kappa:$ & 0.6 & 0.8 \\
$\theta:$ & $0.03(3 \%)$ & $0.0314(3.14 \%)$ \\
$\sigma:$ & 0.4 & 0.4 \\
$\lambda:$ & -0.5 & -0.5 \\
$\frac{2 \kappa \theta}{\gamma+\kappa+\lambda}:$ & $0.0534(5.34 \%)$ & $0.0534(5.34 \%)$ \\
$\frac{\kappa \theta}{\kappa+\lambda}:$ & $0.18(18 \%)$ & $0.0837(8.37 \%)$ \\
\hline
\end{tabular}

The economies in the second example differ with respect to the short horizon monetary parameters in our model. The current spot rate, its long term mean, and the speed of adjustment of the current rate to its average in country $X$ are below the values in country $Y$. However, the long-term yields (6) are the same in both countries.

Approach 1: (Based on term structure) Figure 3 (a) shows the humped term structure in both countries. In the long-run (not visible in figure 4) the convergence of the yields in both countries leads to a convergence of the long-run expected exchange rate to the spot exchange rate at time $t=0$. 
FIG. 3. Example 2: Term structures of interest rates, expected exchange rates, expected depreciation rates;

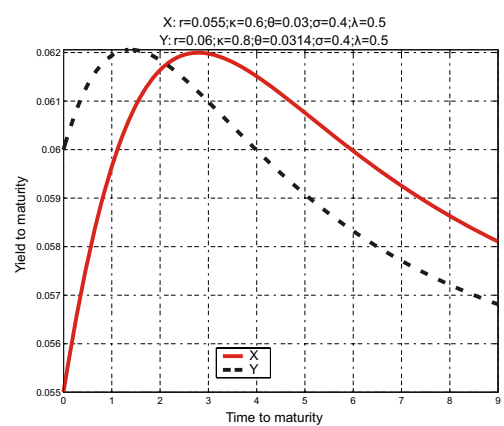

(a) Term Structures: country $X$ solid, country $Y$ dashed

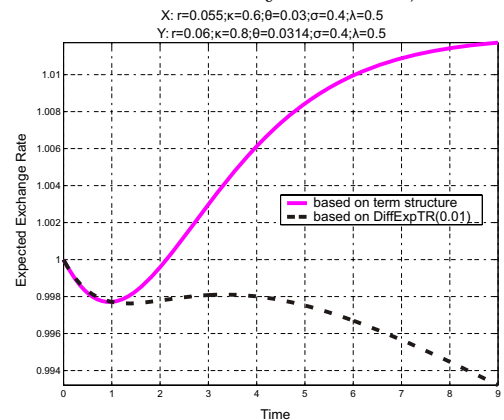

(b) Expected Exchange Rates: approach 1 based on term structures solid, approach 2 based on expected spot rates dashed

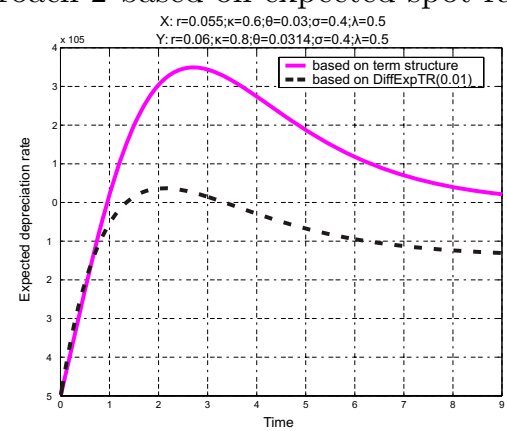

(c) Expected Depreciation Rates: approach 1 based on term structures solid, approach 2 based on expected spot rates dashed

For short horizons however, the lower yields in country $X$ lead to an expected appreciation. While for medium horizons, the slower adjustment of 
the spot interest rate leads to higher yields in country $X$ and subsequently to the expectation of an depreciation in the medium horizon. Figure 3 (b) shows this expectations. As a result, the expected rate of depreciation which is negative in the short-run, becomes positive, and dies out in the long-run as the solid line in figure 3 (c) verifies.

Approach 2: (Based on expected spot rates) 3 (c) shows that the expected rates of depreciation based on the expected future one period total returns show a similar development. However, due to the difference in the long-run average of the spot rates, the expected depreciation rate converges to a level significantly below zero, i.e. the exchange rate is expected to appreciate continuously in the long run (compare the dashed line in 3 (b)).

\section{Example 3:}

TABLE 3.

Parameter values used in example 3: spot interest rate $r$ and parameters of the spot interest rate process: mean reversion $\kappa$, long term value $\theta$, variance $\sigma$; market risk parameter $\lambda$; long term yield $\frac{2 \kappa \theta}{\gamma+\kappa+\lambda}$, and shape parameter $\frac{\kappa \theta}{\kappa+\lambda}$;

\begin{tabular}{|c|c|c|}
\hline Variable & Europe (country X) & USA (country Y) \\
\hline$r:$ & $0.027(2.7 \%)$ & $0.042(4.2 \%)$ \\
$\kappa:$ & 0.2 & 0.41 \\
$\theta:$ & $0.03(3 \%)$ & $0.03(3 \%)$ \\
$\sigma:$ & 0.06 & 0.44 \\
$\lambda:$ & -0.1 & -0.4 \\
$\frac{2 \kappa \theta}{\gamma+\kappa+\lambda}:$ & $0.052(5.2 \%)$ & $0.039(3.9 \%)$ \\
$\frac{\kappa \theta}{\kappa+\lambda}:$ & $0.12(12 \%)$ & $1.23(123 \%)$ \\
\hline
\end{tabular}

Finally, we present two economies featuring the current yield curves of the European Union (country X) and the United States (country Y). The parameters in table 3 are chosen to meet the stylized characteristics of the US and European yield curves in October 2005 and the historic development of the spot rates. The spot exchange rate is set to unity like in the previous academic examples.

Approach 1: (Based on term structure) Figure 4(a) shows the term structure in both countries. Both yield curves are characterized by the spot interest rate. The European spot rate is below the long term yield and implies an upward sloped yield curve. The US spot rate lies slightly above the long term yield and the yield curve is humped. Further, the US yields are well above the European yields for any maturity in the viewed horizon. The interest differential varies with the maturity due to the different shapes of the yield curves. It peaks at a maturity of approximately 2 years and declines for longer maturities. As a consequence, the Euro is expected to 
FIG. 4. Example 3: Term structures of interest rates (Euro solid line, USA dashed line), expected Euro/USD exchange rates and expected depreciation rates (approach 1 solid line, approach 2 dashed line);

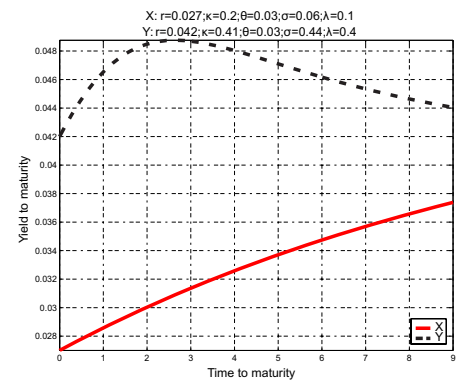

(a) Term Structures: Europe (country $X$ ) solid line, USA (country $Y$ )

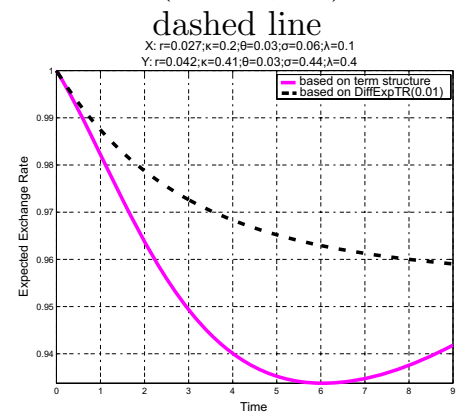

(b) Expected Euro/USD exchange rates: approach 1 based on term structures solid line, approach 2 based on expected spot rates dashed line

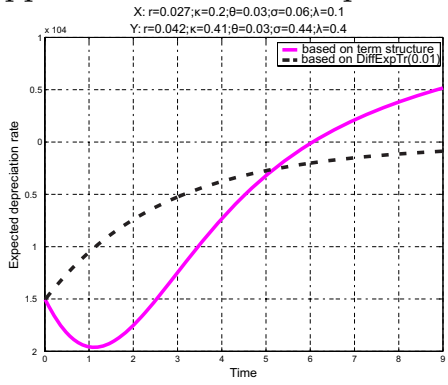

(c) Expected depreciation rates of Euro/USD exchange rate: approach 1 based on term structures solid line, approach 2 based on expected spot rates dashed line

appreciate. Since the expected exchange rate change can be approximated by the product of interest difference and maturity, the expected exchange rate follows a different path (see figure 4(b)). The Euro is expected to 
appreciate for 6 years. Thereafter it is expected to depreciate again as the interest difference for longer maturities declines. The expected depreciation rates (see solid line in figure 4(c)) are negative for the first six years and positive afterwards.

Approach 2: (Based on expected spot rates) The US spot interest rate is higher than its long term value $\theta^{*}$. Thus it is expected to decline in the future towards $\theta^{*} .{ }^{6}$ Conversely, the low European spot interest rate is expected to rise towards $\theta$. Summarized, both spot rates are expected to converge to $\theta=\theta^{*}$ from different sides. The expected difference of the spot rates $\mathbb{E}_{t}\left(r(s)-r^{*}(s)\right)$ is strictly positive and declining. Thus the expected depreciation rate based on this approach is strictly negative and converges to 0 (see dashed line in $4(\mathrm{c})$ ). Consequently, based on this approach the exchange rate is expected to continuously depreciate (see dashed line in figure $4(\mathrm{~b})) .^{7}$

Comparison: Both approaches show an expected appreciation of the Euro/USD exchange rate. The approach based on the differences in the yield curves results in a steep initial expected appreciation of the Euro, which runs out after 6 years and turns into a mild devaluation after that, but expects the Euro not to fall back to its initial level. The approach based on the expected evolution of the spot rates on the other hand implies a continuous but weaker expected appreciation path.

\section{THE INFLUENCE OF THE EXPECTATIONS ON THE SPOT EXCHANGE RATE}

\subsection{The model}

In this section, we develop the reaction function of the spot exchange rate to changes of the spot interest rate. There are several approaches modeling the reactions of both the spot exchange rate and the exchange rate expectations to new information. Changes in the interest differential cause adjustments of either the expected level of the future exchange rate or the spot exchange rate or both. We argue along the lines of the mainstream that expectations on the future level of the exchange rate are more rigid than the spot rates. Changes of the spot interest rate induce changes in the term structure of interest rates. Agents rearrange their portfolios and react to these movements by current foreign currency transactions. Hence, the spot exchange rate adjusts.

\footnotetext{
${ }^{6}$ This argument is a direct consequence from the assumption in the Cox et al. (1985b) model of a mean reverting process generating the spot interest rate.

${ }^{7}$ Neither the different adjustment speeds $\kappa, \kappa^{*}$ nor the risk attitudes $\lambda, \lambda^{*}$ influence this result significantly. Alternative values of $\theta$ and $\theta^{*}$ will alter the results. If $\theta^{*}<\theta$, the US spot rate will be expected to fall below the European spot rate. At this time the exchange rate will be expected to depreciate after the initial appreciation.
} 
In the model in section 3.1, the interest rate term structure in both countries determines the term structure of exchange rate expectations see equation (12)). If the entire interest rate term structure moves as the result of a change in the spot interest rate, in general there exists no value for the spot exchange rate which leaves the term structure of exchange rate expectations entirely unchanged. Thus, both spot exchange rate and expectation adjust to the new situation. The rigidity of the exchange rate expectation is implemented by determining the spot rate as the minimizer of the change in the term structure of the exchange rate expectation. The spot exchange rate adjust in a way such that the differences between the old and the new term structure of exchange rate expectations are minimized. Figure 5 visualizes this idea. ${ }^{8}$

FIG. 5. Spot and expected exchange rates before (solid line) and after (dashed line) a $1 \%$ decrease in the spot interest rate of country $Y$

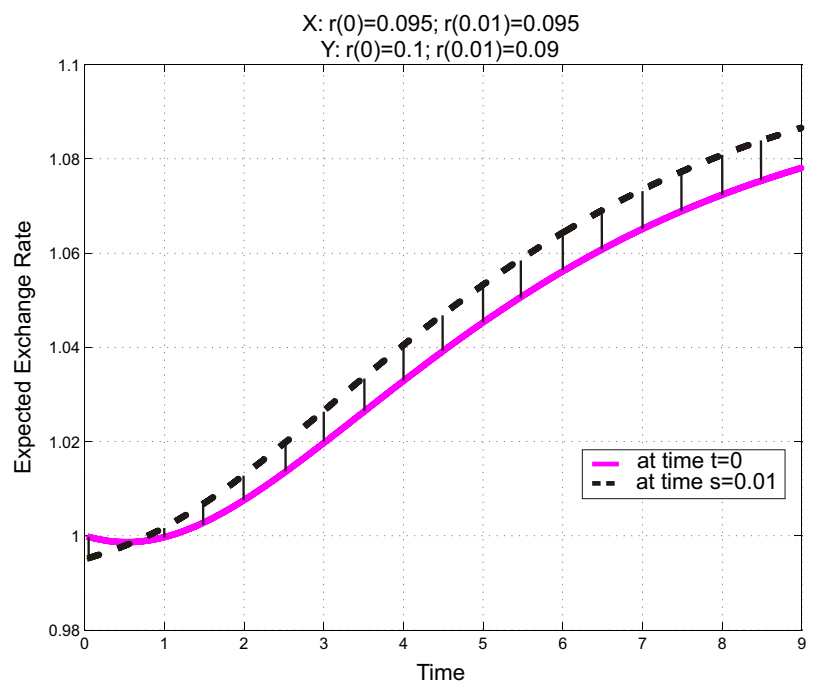

In order to ensure that these differences do not balance themselves out, the differences are squared. Furthermore, the expectations of the distant future are downweighted by introducing the weight $\frac{1}{T}$. The example in figure 5 yields the initial spot rates of $9.5 \%$ and $10 \%$ respectively. At time $s=t+\Delta$ country $Y$ loosens its monetary policy and the spot interest rates settles at $9 \%$. The spot exchange rate adjusts, such that the marked area (in accordance with the weights) is minimized. Consequently, our approach

\footnotetext{
${ }^{8}$ This example is based on the parameter setting of example 2 and will be analyzed in detail below.
} 
analyzes the reaction of the spot exchange rate to unexpected changes in the interest rates.

In technical terms these arguments can be expressed as follows:

$$
\begin{aligned}
\mathcal{E}_{s} & =\arg \min \left\{\int_{s}^{\infty}\left[\mathbb{E}_{t}\left(\mathcal{E}_{T} \mid \mathcal{E}_{t}\right)-\mathbb{E}_{s}\left(\mathcal{E}_{T} \mid \mathcal{E}_{s}\right)\right]^{2} \frac{1}{T} d T\right\} \\
& =\arg \min \left\{\int_{s}^{\infty}\left[\frac{P^{*}\left(r^{*}(t), t, T\right)}{P(r(t), t, T)} \mathcal{E}_{t}-\frac{P^{*}\left(r^{*}(s), s, T\right)}{P(r(s), s, T)} \mathcal{E}_{s}\right]^{2} \frac{1}{T} d T\right\},
\end{aligned}
$$

where $\mathbb{E}_{s}\left(\mathcal{E}_{T} \mid \mathcal{E}_{s}\right)$ stands for the expected exchange rate at time $T$ given the information at time $s$, that is the current interest rate and the spot exchange rate $\mathcal{E}_{s}$.

The integrand of (22) is a continuous function within the investigated interval and can be partially differentiated with respect to $\mathcal{E}_{s}$.Thus, the conditions (A.23) and (A.24) can be used to identify $\mathcal{E}_{s} .{ }^{9}$ The conditions can be written as follows:

$$
\begin{gathered}
\int_{s}^{R} \frac{-2}{T}\left[\frac{P^{*}\left(r^{*}(t), t, T\right)}{P(r(t), t, T)} \mathcal{E}_{t}-\frac{P^{*}\left(r^{*}(s), s, T\right)}{P(r(s), s, T)} \mathcal{E}_{s}\right] \frac{P^{*}\left(r^{*}(s), s, T\right)}{P(r(s), s, T)} d T=0 \\
\int_{s}^{R} \frac{2}{T}\left(\frac{P^{*}\left(r^{*}(s), s, T\right)}{P(r(s), s, T)}\right)^{2} d T>0 .
\end{gathered}
$$

Equation (24) is always satisfied, as bond prices are always positive. Consequently, the spot exchange rate at time $s$ can be calculated by:

$$
\mathcal{E}_{s}=\mathcal{E}_{t} \frac{\int_{s}^{R} \frac{P^{*}\left(r^{*}(t), t, T\right)}{P(r(t), t, T)} \frac{P^{*}\left(r^{*}(s), s, T\right)}{P(r(s), s, T)} \frac{1}{T} d T}{\int_{s}^{R}\left(\frac{P^{*}\left(r^{*}(s), s, T\right)}{P(r(s), s, T)}\right)^{2} \frac{1}{T} d T} .
$$

There seems to exist no analytical solution to the integrals presented in (25). We thus are the strategy of adaptive quadrature to numerically evaluate the expression.

The solution $\mathcal{E}_{s}$ for the spot rate can also be interpreted as the expectation of the spot rate at time $s$ given the information at time $t$ and conditional on the change of the underlying economic variable used to calculate $\mathcal{E}_{s}$. The value of $(25)$ can be interpreted as another expectation of the exchange rate at time $s,{ }^{10}$ if the actual spot rate at time $s$ is replaced by

\footnotetext{
${ }^{9}$ See appendix for details.

${ }^{10}$ Detailed investigations of this third type of rational expectations were not done and it is not compared to the alternative expectations formed in section 3.1 and 3.2.
} 
the expectation of the spot rate at time $s$ given the spot rate at the current time $t$ (equation (A.7)), i.e.

$$
\mathcal{E}_{s}^{e}=\mathcal{E}_{t} \frac{\int_{s}^{R} \frac{P^{*}\left(r^{*}(t), t, T\right)}{P(r(t), t, T)} \frac{P^{*}\left(E\left(r^{*}(s) \mid r^{*}(t)\right), s, T\right)}{P(E(r(s) \mid r(t)), s, T)} \frac{1}{T} d T}{\int_{s}^{R}\left(\frac{P^{*}\left(E\left(r^{*}(s) \mid r *(t)\right), s, T\right)}{P(E(r(s) \mid r(t)), s, T)}\right)^{2} \frac{1}{T} d T} .
$$

\subsection{Examples}

In this section, we present two examples of unexpected changes of the spot interest rate at time $s=\Delta$ influence the spot exchange rate and the exchange rate expectations based on the results of section 4.1.

First, we choose the economies presented in example 2 but change the initial the spot rates at time $t=0$ to $9.5 \%$ in country $X$ and $10 \%$ in country $Y$. Figure 5 displays the results when at time $s=\Delta$ the spot rate in country $Y$ is unexpectedly lowered to $9 \%$, while it doesn't change in country $X$. As the other variables describing both economies have not changed, the long-term yields (6) of both economies have not changed either.

The term structure of the exchange rate expectations, however, differs from the initial structure, because different values of the spot interest rate influence the prices of the bonds (see equation (2)). Due to the lower interest rates in country $Y$, the demand for the currency $Y$ declines which results in an appreciation of the currency of country $X$. The spot exchange rate drops to $E_{1}=0.9951$.

The calculation method minimizes the adjustment of the exchange rate expectations, i.e. the squared weighted differences of the expectations formed at time $t=0$ and those formed at time $s=\Delta$ are minimized. The change of interest rates and the resulting implication on the spot exchange rate are unexpected. At time $t=0$ an temporary appreciation with a following depreciation of country $X$ 's currency is expected (the expected exchange rate lies below unity up to time 1 and above thereafter). The decrease of country $Y$ 's interest rate leads to an appreciation of currency $X$ which is larger than the originally expected one, but raises the level and speed of the expected depreciation. The market expects the effects of the interest rate drop to last only temporarily and lead to an even stronger appreciation of country $Y$ 's currency over a medium horizon.

The size of the immediate spot exchange rate change is only $0.5 \%$ at an interest rate change of $1 \%$, i.e. it is only half as large as the simple form of the interest parity implies. An rigorous analysis of the comparative statics of this semi-elasticity of the spot exchange rate on interest rate changes and the deduction of testable hypotheses is subject of future research. As a rule of thumb for the case of not inverse interest rate term structures, we find that the elasticity of the spot exchange rate on interest rate changes is less 
than unity if the term structure of exchange rate expectations shows opposite directions for short and long horizons. It is less important, whether the interest rate change increases or decreases the initial interest difference, i.e. is in line or contrary to the initial short horizon expectation. Including the entire term structure of interest rates could significantly improve the power of interest parity theory, as the term structure includes market expectations and values of most variables, e.g. inflation or monetary policy, which are assumed to effect the exchange rate.

Secondly, we choose the economies presented in example 3 to illustrate the effects of an interest rise in Europe on the US Dollar Euro exchange rate. We model an increase in the spot interest rate in country $X$ (Europe) from $2.7 . \%$ to $2.95 \%$ by European monetary authorities. ${ }^{11}$ This step leads to an appreciation of its currency and the spot exchange rate declines to $E_{1}=0.9974$. In this case, the elasticity of the spot exchange rate on interest rate changes is close to unity, i.e. the prediction of simple UIP and the UIP term structure approach coincide. ${ }^{12}$ Figure 6 illustrates this example. In this situation the direction of the change of the spot exchange rate at time $s=\Delta$ is consistent with the initial expectation of an appreciating Euro. The appreciation is initially stronger than expected before the interest rate change. However, the rise in the European spot rate and its consequences on the term structure lead to a reduction of the expected level of appreciation of the Euro over a medium horizon. The appreciation is moved up in time but reduced in the expected level. A more intuitive explanation would be that the initial appreciation dampens the expected export rates and thus influences the expected future appreciation rates via market expectations of growth rates and foreign exchange flows.

\section{SUMMARY AND PERSPECTIVES}

In this paper, a model of the term structure of exchange rate expectations is investigated. Nesting the idea of UIP and the term structures of interest rates of Cox et al. (1985b), we construct a path of expected exchange rates. No arbitrage conditions based on the two different term structures lead to an expectation of the future development of the spot exchange rate. Additionally, a second rational expectation is formed using expected interest parity in connection with repeated investment in shortterm bonds. We give an explicit solution of both expectations conditional on fundamental factors.

\footnotetext{
${ }^{11} \mathrm{We}$ use the market spot interest rate as parameter and not the key ECB interest rates for simplicity of the argument.

${ }^{12}$ This example is nearly symmetric, i.e. our model predicts a $0.26 \%$ appreciation of the US Dollar if the new Chairman of the US Federal Reserve Ben Bernanke raises the US spot interest rate another $+0.25 \%$.
} 
FIG. 6. Spot and expected exchange rates before (solid line) and after (dashed line) a $0.25 \%$ increase in the spot interest rate of country $X$ (Europe)

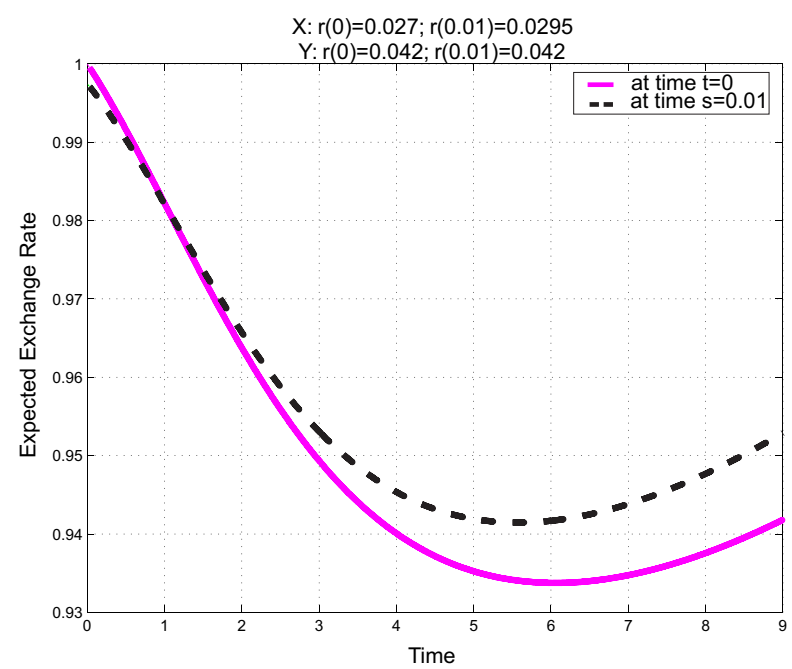

Both expectations for the exchange rate term structure partly show similar and partly show different behavior. If both expectations differ, both can be economically reasonable justified. ${ }^{13}$ The ambiguity of expectations in term structure UIP models might serve as one element in explaining the mixed empirical results known as UIP puzzle.

Finally, we determine the reaction function of the spot exchange rate on changes in fundamental variables based on the term structure of exchange rate expectations. Using numerical integration methods, the semi-elasticity of the spot Euro/USD exchange rate on changes of the US or European spot interest rate is estimated close to unity. This elasticity is influenced by the term structures in both countries and may take values above unity (market overreaction) and or below unity, indicating an dampened market reaction. If the interest rates are not inverse, we get the following rule of thumb. If the exchange rate initially is expected to appreciate over short horizons and depreciate in the long run (or vice versa), then changes of the interest rate affect the spot exchange rate only little. Yet, the medium horizon expectation of the appreciation rates may be affected strongly. If the short

\footnotetext{
${ }^{13} \mathrm{We}$ assume that in the long-run the explanatory and predictive power of both expectations vanishes. The speed of reduction of the explanatory power should be higher for the approach based on iterative investment in short term bonds due to an add up of transaction costs for longer horizons and an increasing uncertainty about the return of future short term bonds.
} 
run and long run exchange rate expectations have the same direction, the immediate effect is strong.

First preliminary empirical results using US, German and Japanese data confirm that firstly, the entire interest rate structure and not only single maturities contains information about changes of the exchange rate, and secondly, the individual interest rates are relevant, and not only their differences. Both findings are robust to changes in currencies and periods.

\section{APPENDIX}

\section{A.1. TABLE OF SYMBOLS}

The following table lists the most important symbols used throughout this work:

\begin{tabular}{|c|c|}
\hline Symbol & Interpretation \\
\hline$t$ & current time; set to 0 (arbitrary) \\
$s$ & future time; $s>t$ \\
$T$ & future time; date of maturity of zero bond \\
$T-t$ & time-to-maturity of zero bond at current time $t$ \\
$\kappa$ & speed of adjustment of spot rate \\
$\theta$ & long-term value of spot rate \\
$\sigma^{2}$ & interest rate variance \\
$\lambda$ & market risk value \\
$r, r(t)$ & current interest rate \\
$r(s)$ & interest rate at future time $s$ \\
$(\cdot)^{*}$ & respective variable of country Y \\
$P(r, t, T)$ & price of zero bond at time $t$ with time-to-maturity $T-t$ and spot rate $r$ \\
$R(r, t, T)$ & yield of zero bond at time $t$ with time-to-maturity $T-t$ and spot rate $r$ \\
$A, B$ & determinants of price and yield of a zero bond respectively \\
$\phi_{1}, \phi_{2}, \phi_{3}$ & determinants of price and yield of a zero bond respectively \\
$\mathcal{E}_{0}$ & starting exchange rate; set to 1 (arbitrary) \\
$\mathcal{E}_{t}$ & exchange rate at current time $t$ \\
$\mathcal{E}_{s}$ & exchange rate at future time $s$ \\
$\mathcal{E}_{s}^{e}$ & expected exchange rate at future time $s$ \\
$\Delta$ & length of period; set to 0.01 in the latter part of this thesis (arbitrary) \\
\hline$d_{s}$ & rate of devaluation at time $s$ \\
\hline $\mathbb{E}_{t}$ & expectation operator conditional on information an time $t$ \\
\hline $\mathbb{E}^{i}\left(d_{s}\right)$ & expected rate of devaluation of approach $i=1,2$ \\
\hline
\end{tabular}




\section{A.2. CALCULATiON OF THE ETR $(\Delta)$}

In order to investigate the characteristics of the expected total one period return $(\operatorname{ETR}(\Delta))$ mentioned above, the expectation needs to be given explicitly in a form dependent on the variables which may influence the behavior. Basically, an explicit form of

$$
\begin{aligned}
\mathbb{E}_{t}\left(R(r(s), s, s+\Delta)^{T R}\right) & =\mathbb{E}_{t}\left(e^{R(r(s), s, s+\Delta) \Delta}-1\right) \\
& =\mathbb{E}_{t}\left(e^{r(s) B(s, s+\Delta)-\ln (A(s, s+\Delta))}\right)-1
\end{aligned}
$$

for a particular future time $s$ is needed. ${ }^{1}$

$A(s, s+\Delta)$ and $B(s, s+\Delta)$ are defined as in (3) and (4) respectively. Obviously $A(s, s+\Delta)$ and $B(s, s+\Delta)$ are constant for any choice of $s$ and independent from the current time $t$ and the spot rate $r(t)$. For an easier notation, $A(s, s+\Delta)$ and $B(s, s+\Delta)$ are replaced by $\bar{A}$ and $\bar{B}$ respectively.

Cox et al. (1985b) show that the probability density of the spot interest rate $r$ at time $s$, conditional on its value at the current time $t$, is given by:

$$
f(r(s), s ; r(t), t)=c e^{-u-v}\left(\frac{v}{u}\right)^{\frac{q}{2}} I_{q}\left(2(u v)^{\frac{1}{2}}\right),
$$

where

$$
\begin{aligned}
c & \equiv \frac{2 \kappa}{\sigma^{2}\left(1-e^{-\kappa(s-t)}\right)} \\
u & \equiv c r(t) e^{-\kappa(s-t)} \\
v & \equiv \operatorname{cr}(s) \\
q & \equiv \frac{2 \kappa \theta}{\sigma^{2}}-1
\end{aligned}
$$

and $I_{q}(\cdot)$ is the modified Bessel function of the first kind of order $q$. The distribution function is the noncentral chi-square, $\chi^{2}[2 \operatorname{cr}(s) ; 2 q+2,2 u]$, with $2 q+2$ degrees of freedom and parameter of noncentrality $2 u$ proportional to the current spot rate. Straightforward calculations give the expected value and variance of $r(s)$ as:

$$
\begin{aligned}
\mathbb{E}(r(s) \mid r(t)) & =r(t) e^{-\kappa(s-t)}+\theta\left(1-e^{-\kappa(s-t)}\right) \\
\operatorname{var}(r(s) \mid r(t)) & =r(t)\left(\frac{\sigma^{2}}{\kappa}\right)\left(e^{-\kappa(s-t)}-e^{-2 \kappa(s-t)}\right) \\
& +\theta\left(\frac{\sigma^{2}}{2 \kappa}\right)\left(1-e^{-\kappa(s-t)}\right)^{2} .
\end{aligned}
$$

\footnotetext{
${ }^{1}$ Note that for $s=t$ the expectation is already known. It is equivalent to the total return of a bond with time-to-maturity $T-t=\Delta$, which is known from the term structure. When dealing with the expectation, therefore, one can assume $s>t$.
} 
The current interest rate $r(t)$ influences the value of $u$, which is defined as in (A.4).

First of all, the probability density of a distribution function, which is noncentral chi-square with $n$ degrees of freedom and a parameter of noncentrality of $\lambda>0$, needs to satisfy the following condition:

$$
\int_{0}^{\infty} \frac{1}{2} e^{-\frac{x+\lambda}{2}}\left(\frac{x}{\lambda}\right)^{\frac{n-2}{4}} I_{\frac{n-2}{2}}\left((\lambda x)^{\frac{1}{2}}\right) d x=1 .
$$

With

$$
\begin{aligned}
\bar{v} & =v-r(s) \bar{B} \\
& =r(s)(c-\bar{B}) \\
\bar{u} & =\frac{u v}{\bar{v}} \\
& =\frac{u c}{c-\bar{B}},
\end{aligned}
$$

where $\bar{u}>0$, and (A.2), the expectation of $e^{r(s) \bar{B}-\ln (\bar{A})}$ can be written as follows:

$$
\begin{aligned}
& \mathbb{E}_{t}\left(e^{r(s) \bar{B}-\ln (\bar{A})}\right) \\
& =\int_{0}^{\infty} e^{r(s) \bar{B}-l n(\bar{A})} c e^{-u-v}\left(\frac{v}{u}\right)^{\frac{q}{2}} I_{q}\left(2(u v)^{\frac{1}{2}}\right) d r(s) \\
& =\int_{0}^{\infty} \frac{c}{\bar{A}} e^{r(s) \bar{B}-u-v\left(\frac{v}{u}\right) \frac{q}{2}} I_{q}\left(2(\bar{u} \bar{v})^{\frac{1}{2}}\right) d r(s) \\
& =\int_{0}^{\infty} \frac{c}{\bar{A}} e^{\bar{u}-u} e^{-\bar{u}-\bar{v}\left(\frac{v}{u}\right)^{\frac{q}{2}}} I_{q}\left(2(\bar{u} \bar{v})^{\frac{1}{2}}\right) d r(s) \\
& =\int_{0}^{\infty} \frac{c}{\bar{A}}\left(\frac{1}{c}\right)^{-q}\left(\frac{1}{c}\right)^{q}(c-\bar{B})^{-q}(c-\bar{B})^{q} e^{\bar{u}-u} e^{-\bar{u}-\bar{v}}\left(\frac{v}{u}\right)^{\frac{q}{2}} I_{q}\left(2(\bar{u} \bar{v})^{\frac{1}{2}}\right) d r(s) \\
& =\int_{0}^{\infty} \frac{c}{\bar{A}}\left(\frac{1}{c}\right)^{-q}(c-\bar{B})^{-q} e^{\bar{u}-u} e^{-\bar{u}-\bar{v}}\left(\frac{r(s)(c-\bar{B})}{\frac{u c}{c-\bar{B}}}\right)^{\frac{q}{2}} I_{q}\left(2(\bar{u} \bar{v})^{\frac{1}{2}}\right) d r(s) \\
& =\int_{0}^{\infty} \frac{c}{\bar{A}}\left(\frac{c-\bar{B}}{c}\right)^{-q} e^{\bar{u}-u} e^{-\bar{u}-\bar{v}}\left(\frac{\bar{v}}{\bar{u}}\right)^{\frac{q}{2}} I_{q}\left(2(\bar{u} \bar{v})^{\frac{1}{2}}\right) d r(s) .
\end{aligned}
$$


Using the substitution $n=2 q+2, \lambda=2 \bar{u}$, and $x=2 \bar{v}$ and considering the chain rule of differentiation, (A.10) is equivalent to

$$
\begin{aligned}
1 & =\int_{0}^{\infty} \frac{1}{2} e^{-\frac{x+\lambda}{2}}\left(\frac{x}{\lambda}\right)^{\frac{n-2}{4}} I_{\frac{n-2}{2}}\left((\lambda x)^{\frac{1}{2}}\right) d x \\
& =\int_{0}^{\infty} \frac{1}{2} e^{-\frac{x+\lambda}{2}}\left(\frac{x}{\lambda}\right)^{\frac{q}{2}} I_{q}\left((\lambda x)^{\frac{1}{2}}\right) d x \\
& =\int_{0}^{\infty} \frac{1}{2} e^{-\frac{x+2 \bar{u}}{2}}\left(\frac{x}{2 \bar{u}}\right)^{\frac{q}{2}} I_{q}\left((2 \bar{u} x)^{\frac{1}{2}}\right) d x \\
& =\int_{0}^{\infty} \frac{1}{2} e^{-\bar{u}-\bar{v}}\left(\frac{\bar{v}}{\bar{u}}\right)^{\frac{q}{2}} I_{q}\left(2(\bar{u} \bar{v})^{\frac{1}{2}}\right) 2 d v \\
& =\int_{0}^{\infty} e^{-\bar{u}-\bar{v}}\left(\frac{\bar{v}}{\bar{u}}\right)^{\frac{q}{2}} I_{q}\left(2(\bar{u} \bar{v})^{\frac{1}{2}}\right)(c-\bar{B}) d r(s) .
\end{aligned}
$$

As a result, considering (A.16) together with the fact that $A(s, s+\Delta)$, $B(s, s+\Delta), u, \bar{u}$, and $c$ are constant, the expectation (A.13) can be written as:

$$
\begin{aligned}
& \mathbb{E}_{t}\left(e^{r(s) \bar{B}-\ln (\bar{A})}\right) \\
& =\int_{0}^{\infty} \frac{c}{\bar{A}}\left(\frac{c-\bar{B}}{c}\right)^{-q} e^{\bar{u}-u} e^{-\bar{u}-\bar{v}}\left(\frac{\bar{v}}{\bar{u}}\right)^{\frac{q}{2}} I_{q}\left(2(\bar{u} \bar{v})^{\frac{1}{2}}\right) d r(s) \\
& =\frac{c}{\bar{A}}\left(\frac{c-\bar{B}}{c}\right)^{-q} e^{\bar{u}-u} \frac{1}{c-\bar{B}} \int_{0}^{\infty} e^{-\bar{u}-\bar{v}}\left(\frac{\bar{v}}{\bar{u}}\right)^{\frac{q}{2}} I_{q}\left(2(\bar{u} \bar{v})^{\frac{1}{2}}\right)(c-\bar{B}) d r(s) \\
& =\frac{c}{\bar{A}}\left(\frac{c-\bar{B}}{c}\right)^{-q} e^{\bar{u}-u} \frac{1}{c-\bar{B}} \\
& =\frac{1}{\bar{A}}\left(\frac{c}{c-\bar{B}}\right)^{q+1} e^{\frac{u \bar{B}}{c-\bar{B}}} \\
& =\frac{1}{A(s, s+\Delta)}\left(\frac{c}{c-B(s, s+\Delta)}\right)^{q+1} e^{\frac{u B(s, s+\Delta)}{c-B(s, s+\Delta)}}
\end{aligned}
$$

Hence, the expression (A.1) is equivalent to:

$$
\mathbb{E}_{t}\left(R(r(s), s, s+\Delta)^{T R}\right)=\frac{e^{\frac{u B(s, s+\Delta)}{c-(s, s+\Delta)}}}{A(s, s+\Delta)}\left(\frac{c}{c-B(s, s+\Delta)}\right)^{q+1}-1
$$


Furthermore, expression (16) can be written as:

$$
\begin{aligned}
\left(\frac{\mathcal{E}_{s+\Delta}^{e}-\mathcal{E}_{s}^{e}}{\mathcal{E}_{s}^{e}}\right)_{2}=\frac{\frac{1}{\bar{A}}\left(\frac{c}{c-\bar{B}}\right)^{q+1} e^{\frac{u \bar{B}}{c-\bar{B}}}-\frac{1}{\bar{A}^{*}}\left(\frac{c^{*}}{c^{*}-\bar{B}^{*}}\right)^{q^{*}+1} e^{\frac{u^{*} \bar{B}^{*}}{c^{*}-\bar{B}^{*}}}}{\frac{1}{\bar{A}^{*}}\left(\frac{c^{*}}{c^{*}-\bar{B}^{*}}\right)^{q^{*}+1} e^{\frac{u^{*} \bar{B}^{*}}{c^{*}-B^{*}}}} \\
=\frac{\overline{A^{*}}}{\bar{A}}\left(\frac{c}{c-\bar{B}}\right)^{q+1}\left(\frac{c^{*}-\bar{B}^{*}}{c^{*}}\right)^{q^{*}+1} e^{\frac{u \bar{B}}{c-B}-\frac{u^{*} \bar{B}^{*}}{c^{*}-B^{*}}}-1 .
\end{aligned}
$$

Calculations lead to an expected future one period total return in the longrun of:

$$
\begin{aligned}
Y l & =\lim _{s \rightarrow \infty} \frac{1}{A(s, s+\Delta)}\left(\frac{c}{c-B(s, s+\Delta)}\right)^{q+1} e^{\frac{u B(s, s+\Delta)}{c-B(s, s+\Delta)}}-1 \\
& =\frac{1}{\bar{A}}\left(\frac{\frac{2 \kappa}{\sigma^{2}}}{\frac{2 \kappa}{\sigma^{2}}-\bar{B}}\right)^{\frac{2 \kappa \theta}{\sigma^{2}}}-1 .
\end{aligned}
$$

\section{A.3. CHARACTERISTICS OF THE $\operatorname{ETR}(\Delta)$}

In this section, we present the results of the analysis of the $\operatorname{ETR}(\Delta)$, $\Delta=0.01$ based on the explicit form evolved in section ??. That is, the characteristics of

$$
\mathbb{E}_{t}\left(R(r(s), s, s+\Delta)^{T R}\right)=\mathbb{E}_{t}\left(e^{r(s) B(s, s+\Delta)-\ln (A(s, s+\Delta))}\right)-1
$$

are investigated.

As mentioned above, the expected future one period total return at time $s=0$ is already known from the term structure. Hence, the behavior of the expected yield at time $s=t=0$ is also known.

Before presenting the results and visualizations of various examples, we theoretically show the validity of our results. First of all, we introduced several intervals for possible and economic reasonable values of the variables. As a starting point, we refer to Chatter-jee (2004). In this paper, quasi-maximum likelihood estimates of the model parameters are obtained by using a Kalman filter to calculate the likelihood function. Furthermore, estimates of $\sigma^{2}$ presented by Brown and Dybvig (1986) were used to cut down the intervals to reasonable lengths. The bank base rates of the FED and the ECB of the last decades serve as a framework for the variables $\theta$ and $r$. Additionally, the conditions (1) on the variables from Cox et al. (1985b) were used. A further condition stemming from the assumption that there exists a liquidity preference can be written as:

$$
\sigma<\sqrt{-2 \kappa \lambda}
$$


Table 1 gives an overview of the intervals.

TABLE 1.

Ranges of the variables used for the numerical analysis of the characteristics of the $\operatorname{ETR}(\Delta)$

\begin{tabular}{|c|c|c|}
\hline Variable & Interval & Increment \\
\hline$\kappa$ & {$[0.1,1]$} & 0.05 \\
$\theta$ & {$[0.005,0.08]$} & 0.00025 \\
$r$ & {$[0.005,0.12]$} & 0.00025 \\
$\lambda$ & {$[-(\kappa-0.05),-0.05]$} & 0.05 \\
$\sigma$ & {$[0.05, \min (\sqrt{-2 \kappa \lambda}, 1)]$} & 0.05 \\
\hline
\end{tabular}

We calculated the partial derivatives analytically, however, it was not trivial to prove an unambiguous behavior for any composition of the variables. Instead, we used the partial derivatives to give evidence considering the characteristics of (A.19) by calculating the maximum and minimum, respectively, for any composition of the variables within the intervals mentioned above and proved the continuity of the partial derivatives. A positive minimum indicates that the expectation increases with an increase in the particular variable, while a negative maximum indicates that the expectation decreases with an increase in the particular variable. It is easy to show that all partial derivatives are continuous functions within the investigated intervals. This can be seen if one considers that any partial derivative of (A.19) is a combination of products, sums and fractions of the several elements of (A.19) and their partial derivatives. Considering the conditions on the variables, we split up equation (A.19) into several components and proved their continuity. According to the characteristics of continuous functions, the continuity of the several components and their partial derivatives, respectively, and the examination, whether the several parts and their various combinations are well defined, are sufficient for the proof of continuity. Consequently, we could easily show the continuity of function (A.19). These results substantiate our propositions.

At this point, we present the behavior of the expectation. Note that another choice of the length of one period, e.g. $\Delta=0.1$, influences the value of the $\operatorname{ETR}(\Delta)$ in the long-run. This follows from (A.19) for $s \rightarrow \infty$. The value increases as the term increases. Moreover, the expected future one period total return at any time increases as the term increases. The result is not surprising, as bonds with a longer maturities achieve a higher total return.

As mentioned in section 2, we assume that the inequation (8) holds and that the expected future one period total return can be approximated by $e^{E(r(s) \mid r(t)) 0.01}-1$. Considering (A.7), for $s \rightarrow 0$ the ETR $(\Delta)$ can be approximated by $e^{r \cdot \Delta}-1$ (for $s \rightarrow \infty$ it can be approximated by $e^{\theta \cdot \Delta}-1$ ). 
Furthermore, for $\Delta=0.01$ the approximation $e^{r \cdot 0.01} \approx 1+r \cdot 0.01$ for small $r \cdot 0.01$ is used. According to Table 1, it can be assumed that the size of $r$ is sufficiently small to allow for this approximation.

While the ETR (0.01) is rising if $r \cdot 0.01$ is below the value in the long-run, the ETR (0.01) is falling otherwise.

Moreover, several other comparative statics for the yield curve are obtained.

Calculations have shown that an increase in the current interest rate increases the ETR (0.01) at any future time $s .{ }^{2}$ This can be easily interpreted if one considers that a bond's yield is a composition of the spot rate and a premium. A higher spot rate influences the expectations concerning the one period total returns, as a higher value of spot rate indicates greater yields. The long-term value of the spot rate, $\theta$, has not changed and, therefore, the expected one period yields in the long-run have not changed very much. Hence, the effect is greater for the expectations in the relatively near future.

FIG. 1. Effect of an increase in $r$ on the $\operatorname{ExpTR}(0.01)$

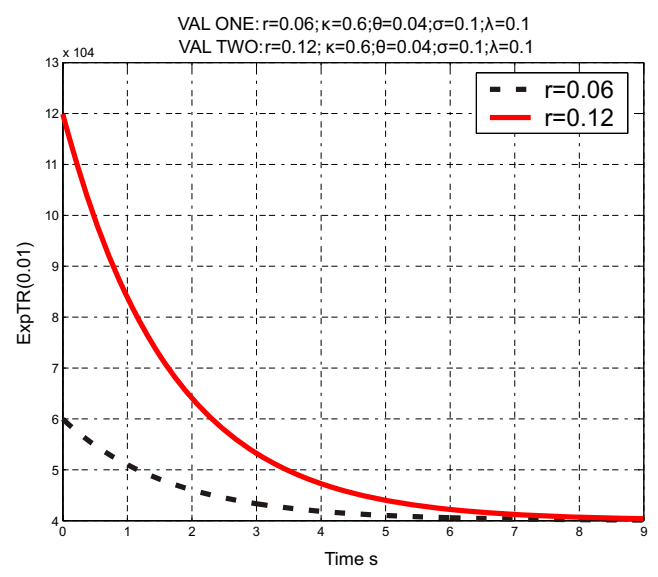

Similarly, an increase in the steady state mean $\theta$ increases the ETR (0.01). Here the effect is greater for the expectations in the relatively distant future as the long-term value $\theta$ has changed, whereas the current interest rate $r$ has not.

The effect of a change in $\kappa$ may be of either sign depending on the current interest rate, that is, the expected value is an increasing function

\footnotetext{
${ }^{2}$ The influence of the various parameters on the total return of a one period bond at time $s=0$ is determined by the term structure. It coincides with the effects described here. An extensive analysis of this special case may be found in Cox et al. (1985b).
} 
of the speed of adjustment parameter $\kappa$ if the spot rate is less than $\theta$ and a decreasing function of $\kappa$ if the spot rate is greater than $\theta$ respectively. This can be seen if one considers that a higher value of $\kappa$ means that the spot rate adjusts faster to a higher/lower level.

The ETR (0.01) decreases as $\lambda$ increases. This can be easily seen as one remembers that higher values of $\lambda$ indicate lower premiums as $\lambda$ is the market value of risk. As $\lambda$ increases (since $\lambda$ is negative this corresponds to a decrease in $|\lambda|$ ), the value of risk decreases. This development influences the expectation of the agent. A lower market value of risk decreases the expected one period yield and, consequently, the total return. The influence on the total return of a one period bond at time $s=0$ is the same.

Hence, for all named parameters the behavior of the expectation is consistent with the behavior of the term structure presented by Cox et al. (1985b).

The effect of an increase in $\sigma^{2}$, however, is not unambiguous: for the particular choice of the variables (see figure 2) it increases the ETR (0.01). The effect of a change of $\sigma^{2}$ on the (expected) yield at time $s=0$ is already known (see Cox et al. (1985b)). A higher value of the variance of the interest rate, $\sigma^{2}$, indicates more uncertainty about future real production opportunities, and thus more uncertainty about future consumption. As a consequence, the guaranteed claim in a bond is valued more highly by investors and the yield decreases. Compared with that, the ETR (0.01) increases at any time $s$.

FIG. 2. Effect of an increase in $\sigma^{2}$ on the $\operatorname{ExpTR}(0.01)$

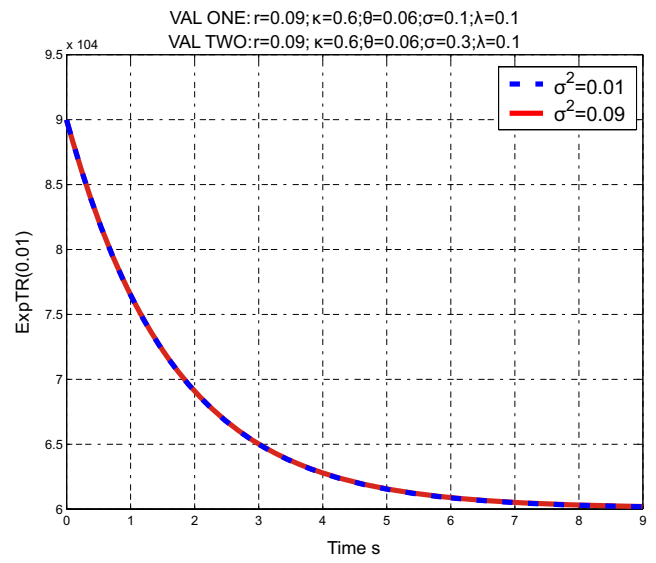

Moreover, a change of the length of one period influences the impact of a change in $\sigma^{2}$ on the ETR (0.01). Longer periods change the influence of changes in $\sigma^{2}$ on the expectations. For example, with $\Delta=2.5$, and given 
the particular values of the variables as in figure 2, an increase in $\sigma^{2}$ leads to a contrary statement. Here, an increase in the variance of the spot rate leads to a decrease of the ETR (2.5).

This phenomenon raises the following questions:

(1) Why does an increase in the variance of the spot rate, which usually indicates a higher uncertainty about real production opportunities, result in higher expected one period yields in the future if the length of the period is chosen to be 0.01 ?

(2) Why does the length of the period seem to influence this result in the one or the other direction?

\section{A.4. THE LIQUIDITY PREFERENCE HYPOTHESIS}

The condition expressing the Liquidity Preference can be easily understood if the results of Cox et al. (1985b) are combined with the explicit form of the $\operatorname{ETR}(\Delta)$ presented in Subsection ??

If one assumes that the expected future one period total return at time $s$ can be approximated by $e^{E(r(s) \mid r(t)) B(s, s-t)-\ln (A(s, s-t))}-1$, where $E(r(s) \mid r(t))$ is calculated as in (A.7). As stated in section 2, the yield (5) approaches the spot rate as maturity nears. Consequently, the assumption of a liquidity preference for bonds with a maturity date in the sufficiently distant future can now be written as (see equation (8)):

$$
e^{r(t) \Delta} e^{E(r(t+\Delta) \mid r(t)) \Delta} \cdots e^{E(r(T) \mid r(t)) \Delta}<e^{R(r, t, T)(T-t)} .
$$

If the maturity date is in the sufficiently distant future, the yield-to-maturity $R(r, t, T)$ is approximately $R(r, t, \infty)$ and, considering (A.7), the expected spot rate given the current interest rate $E(r(T) \mid r(t))$ is approximately $\theta$. If the inequation $R(r, t, \infty)>\theta$ is valid, there is a date of maturity $T$ such that inequation (A.20) holds.

Although $e^{E(r(s) \mid r(t)) B(s, s-t)-\ln (A(s, s-t))}-1$ is not the correct expected future one period total return as

$$
\mathbb{E}\left(e^{r(s) B(s, s-t)-\ln (A(s, s-t))}\right) \neq e^{E(r(s) \mid r(t)) B(s, s-t)-\ln (A(s, s-t))},
$$

it can be shown that for a sufficiently short length of one period the approximation

$$
\mathbb{E}\left(e^{R(r(s), s, s+\Delta) \Delta}\right) \approx e^{E(r(s) \mid r(t)) \Delta},
$$


can be proven valid. This can be seen if one considers a sufficiently small $\Delta$ such that

$$
\begin{aligned}
e^{\gamma \Delta} & \approx 1+\gamma \Delta \\
(\gamma+\kappa+\lambda) \Delta+2 & \approx 2 \\
\ln \left(\frac{c}{c-\Delta}\right) & \approx \frac{c}{c-\Delta}-1 \\
\frac{\Delta}{c-\Delta} & \approx \frac{\Delta}{c}
\end{aligned}
$$

Consequently,

$$
\begin{aligned}
B(s, s+\Delta) & =\frac{2\left(e^{\gamma \Delta}-1\right)}{(\gamma+\kappa+\lambda)\left(e^{\gamma \Delta}-1\right)+2 \gamma} \\
& \approx \frac{2 \Delta \gamma}{(\gamma+\kappa+\lambda) \Delta \gamma+2 \gamma} \\
& =\frac{2 \Delta}{(\gamma+\kappa+\lambda) \Delta+2} \\
& \approx \frac{2 \Delta}{2} \\
& =\Delta
\end{aligned}
$$

and analogous to that

$$
A(s, s+\Delta) \approx 1
$$

Hence,

$$
\begin{aligned}
& \mathbb{E}\left(R(r(s), s, s+\Delta)^{T R}\right)= \\
&= \frac{1}{A(s, s+\Delta)}\left(\frac{c}{c-B(s, s+\Delta)}\right)^{q+1} e^{\frac{u B(s, s+\Delta)}{c-B(s, s+\Delta)}}-1 \\
& \approx\left(\frac{c}{c-\Delta}\right)^{q+1} e^{\frac{u \Delta}{c-\Delta}}-1 \\
&=e^{\frac{2 \kappa \theta}{\sigma^{2}} \ln \left(\frac{c}{c-\Delta}\right)} e^{\frac{c r(t) e^{-\kappa(s-t)}}{c-\Delta}}-1 \\
& \approx e^{\frac{2 \kappa \theta}{\sigma^{2}}\left(\frac{c}{c-\Delta}-1\right)} e^{r(t) e^{-\kappa(s-t)} \Delta}-1 \\
&=e^{\frac{2 \kappa \theta}{\sigma^{2}} \frac{\Delta}{c-\Delta}} e^{r(t) e^{-\kappa(s-t)} \Delta}-1 \\
& \approx e^{\frac{2 \kappa \theta}{\sigma^{2}} \frac{\Delta \sigma^{2}\left(1-e^{-\kappa(s-t)}\right)}{2 \kappa}} e^{r(t) e^{-\kappa(s-t)} \Delta}-1 \\
&=e^{r(t) e^{-\kappa(s-t)}+\theta\left(1-e^{-\kappa(s-t)}\right)}-1 \\
&=e^{E(r(s) \mid r(t))}-1 .
\end{aligned}
$$


Consequently, the condition $R(r, t, \infty)>\theta$ also ensures a liquidity preference if the correct expected future one period total returns are investigated.

\section{A.5. CONDITIONS FOR THE SOLUTION OF THE MINIMIZING PROBLEM TO CALCULATE THE REACTION FUNCTION OF THE SPOT EXCHANGE RATE}

The definite integral

$$
F(y)=\int_{a}^{b} f(x, y) d x
$$

is called integral with parameter. If the function $f$ is defined within an interval $[c, e]$ and the integrand is continuous within $[a, b] \times[c, e]$ and is partially differentiable with respect to $y$, then

$$
\frac{d}{d y} \int_{a}^{b} f(x, y) d x=\int_{a}^{b} \frac{\partial f(x, y)}{\partial y} d x
$$

for an arbitrary $y$ within the interval $[c, e]$. Thus, a minimum of (A.22) needs to satisfy the following conditions:

$$
\begin{gathered}
F^{\prime}(y)=\int_{a}^{b} \frac{\partial f(x, y)}{\partial y} d x=0 \\
F^{\prime \prime}(y)=\int_{a}^{b} \frac{\partial^{2} f(x, y)}{\partial y^{2}} d x>0 .
\end{gathered}
$$

The initial type of problem can be interpreted as finding the argument minimizing the integral on the right hand side of (22), which depends on the parameter $\mathcal{E}_{s}$.

Although the integral in (22) is an improper integral as the upper limit is infinite, we restricted our investigation of the solution to a closed interval $[t, R]$ for technical reasons. This approach imposes no restriction, as the value of $R$ may be arbitrarily large and the impact of not included expectations disappears as the horizon tends to infinity. Moreover, the weight

$\frac{1}{T}$ decreases the importance of those expectations for the determination of $\mathcal{E}_{s}$.

\section{REFERENCES}

Brown, S.J. and P.H. Dybwig, 1986. The Empirical Implications of the Cox, Ingersoll, Ross Theory of the Term Structure of Interest Rates. The Journal of Finance XLI(3), 617-632.

Chaboud, Alan P. and Jonathan H. Wright, 2005. Uncovered interest parity: It works, but not for long. Journal of international economics 66(2) , 349-362. 
Chatterjee, Rana, 2004. Application of the Kalman Filter for Estimating Continuous Time Term Structure Models: Evidence from the UK and Germany. Computing in Economics and Finance 346, Society for Computational Economics.

Chinn, Menzie D. and Guy Meredith, 2004. Monetary policy and long-horizon uncovered interest parity. International monetary fund staff papers 51, 409-430.

Chinn, Menzie D. and Guy Meredith, 2005. Testing uncovered interest parity at short and long horizons. NBER working papers, 11077.

Cox, John C., Jonathan E. Jr. Ingersoll, and Stephen A. Ross, 1985a. An Intertemporal General Equilibrium Model of Asset Prices. Econometrica 53, 363-384.

Cox, John C., Jonathan E. Jr. Ingersoll, and Stephen A. Ross, 1985b. A Theory of the Term Structure of Interest Rates. Econometrica 53, 385-407.

Deutsche Bundesbank, 2005. Exchange rates and interest differentials: recent developments since the introduction of the Euro. Monthly Report July, Deutsche Bundesbank.

Frankel, Jeffrey and Kenneth A. Froot, 1987. Using survey data to test standard propositions regarding exchange rate expectations. American economic review $\mathbf{7 7}$, $133-135$.

Frankel, Jeffrey and Kenneth A. Froot, 1989. Forward discount bias: Is it an exchange risk premium? Quarterly journal of economics 104, 139-161.

Froot, Kenneth A. and Richard H. Thaler, 1990. Foreign exchange. Journal of economic perspectives 4(3), 179-192.

Grilli, Vittorio and Nouriel Roubini, 1995. Liquidity and exchange rates: Puzzling evidence from the g-7 countries. Yale university, mimeo.

Grilli, Vittorio and Nouriel Roubini, 1996. Liquidity models in open economies: Theory and empirical evidence. European economic review 40, 847-859.

Incia, Ahmet Can and Biao Lub, 2007. Currency futures-spot basis and risk premium. Journal of International Financial Markets, Institutions and Money 17(2), 180-197.

Krugman, Paul R. and Maurice Obstfeld, 2003. International Economics - Theory and Policy, 6 ed., Boston: Addison Wesley.

Lewis, Karen K., 1995. Puzzles in International Financial Markets, in Gene Grossman and Kenneth Rogoff, eds. The Handbook of International Economics, vol. III. Amsterdam: North-Holland, pp. 1913-1949.

Mark, Nelson and Yangru Wu, 1998. Rethinking deviations from uncovered interest parity: The role of covariance risk and noise. The economic journal 108(451), 16861706.

Pavlova, Anna and Roberto Rigobon, 2007. Asset Prices and Exchange Rates. Review of Financial Studies 20(4), 1139-1180. 